\title{
Perfil epidemiológico das hepatites infectocontagiosas no estado do Pará
}

\author{
Epidemiological profile of infect-contagious hepatitis in the state of Pará
}

Perfil epidemiológico de hepatitis infectocontagiosas en el estado de Pará

Diana do Vale Leão ${ }^{1 *}$, Rosangela Jaques Belém ${ }^{1}$, Kamila Veras Almeida ${ }^{1}$, Vera Lúcia Ribeiro dos Reis ${ }^{1}$, Herald Souza dos Reis ${ }^{2}$, Fabiolla da Silva dos Santos ${ }^{1}$.

\section{RESUMO}

Objetivo: Analisar e discutir os dados sobre as hepatites infectocontagiosas para melhor compreender o cenário dessas doenças no estado do Pará. Métodos: Foram analisados dados do Boletim de Hepatites Virais/2020 e do DATASUS das hepatites infectocontagiosas B, C e D no Pará entre os anos de 2009-2018. Foram analisados a quantidade de incidência, óbitos e os grupos afetados: raça, sexo, faixa etária e mecanismos de infecção. Resultados: O número de casos confirmados das hepatites B e C continuam aumentando ao longo do tempo. O HBV apresenta a maior quantidade de casos. O HCV é a hepatite infectocontagiosa que mais apresenta óbitos. Entre os grupos afetados para ambas as hepatites, a raça mais acometida foram os pardos e as faixas etárias foram de 20 a 39 e de 40 a 59 anos. Entre os gêneros masculino e feminino, somente o HCV apresentou mais casos em um dos gêneros, sendo mais prevalente nos homens. O mecanismo de transmissão de maior expressão foi o sexual (HBV/HCV) e água (HDV). Conclusão: A transmissão das hepatites virais no estado do Pará continua aumentando ao longo do tempo. São necessárias medidas para diminuir a quantidade de pessoas infectadas, principalmente nos grupos mais afetados.

Palavras-chave: HBV, HCV, HDV, Epidemiologia, Hepatites virais.

\begin{abstract}
Objective: Analyze and discuss infectious and contagious hepatitis data to better comprehend the disease setting in the state of Pará. Methods: Data from the Boletim de Hepatites Virais/2020 and DATASUS from infectious hepatitis B, C, and D in Pará between 2009-2018 were analyzed. The number of incidences, deaths, and affected groups (race, sex, age group, and mechanisms of infection) were analyzed. Results: The confirmed cases numbers of hepatitis $B$ and $C$ continue increasing over time. HBV has the highest case numbers. HCV is the most contagious infectious hepatitis. Among the groups affected for both hepatitis, the most affected race was 'pardo' and in the age groups were 20 to 39 and 40 to 59 years old. Among the male and female genders, only HCV affected more a gender, being more prevalent in men. The transmission mechanism of greatest expression was sexual (HBV/HCV) and water (HDV). Conclusion: The transmission of viral hepatitis in the state of Pará continues to increase over time. Strategies are needed to decrease the number of people infected, especially in the most affected groups.
\end{abstract}

Keywords: HBV, HCV, HDV, Epidemiology, Viral hepatitis.

\section{RESUMEN}

Objetivo: Analizar y discutir los datos sobre las hepatitis infectocontagiosas para un mejor entendimiento en el ambiente de esas enfermedades en el estado de Pará. Métodos: Fueron analizados datos del Boletín de Hepatitis Virales/2020 y del DATASUS de las hepatitis infectocontagiosas B, C y D en Pará entre los años de 2009-2018. Fueron analizados la cantidad de incidencia, óbitos y los grupos afectados: raza, sexo, rango de edad y mecanismos de infección. Resultados: El número de casos confirmados de las hepatitis B y C continúan aumentando a lo largo del tiempo. El HBV presenta la mayor cantidad de casos. El HCV es la

${ }^{1}$ Escola Superior da Amazônia (ESAMAZ), Belém - PA. *E-mail: dianavalebiology@gmail.com

${ }^{2}$ Universidade Federal do Pará (UFPA), Belém - PA. 
hepatitis infectocontagiosa que más representa óbitos. Entre los grupos afectados para ambas hepatitis, la raza más infectada fueron personas de piel morena y los rangos de edad fueron de 20 a 39 y de 40 a 59 años. Entre los géneros masculino y femenino, solamente el HCV mostró un número mayor de infectados en uno de los géneros, siendo más sobresaliente en los hombres. El mecanismo de transmisión de mayor expresión fue el sexual (HBV/HCV) y agua (HDV). Conclusión: La transmisión de las hepatitis virales en el estado de Pará continúa aumentando a lo largo del tiempo. Son necesarias medidas para disminuir la cantidad de personas infectadas, principalmente en los grupos más afectados.

Palabras clave: HBV, HCV, HDV, Epidemiología, Hepatitis virales.

\section{INTRODUÇÃO}

As hepatites virais são doenças causadas por organismos hepatotrópicos e são caracterizadas por serem doenças distintas causadas por vírus diferentes, com características específicas, como variação entre seu material genético que pode ser RNA ou DNA e a presença ou ausência de envelope viral (PAULA VS, et al., 2015). Estas doenças possuem uma variedade de manifestações clínicas e possuem muitas similaridades em suas manifestações clínicas. As manifestações das hepatites virais podem ser assintomáticas, graves e fulminantes (MACEDO TFS, et al., 2014; BRASIL, 2018, TIMÓTEO MVF, et al., 2020). As hepatites B, C e D pertencem respectivamente às famílias Hepadnaviridae, Flaviridae e Deltaviridae (ICTV, 2019).

As hepatites infectocontagiosas $B, C$ e D, causadas respectivamente pelos vírus HBV (Hepatitis $B$ virus), HCV (Hepatitis C virus) e HDV (Hepatitis D virus) compartilham o mesmo tipo de transmissão parenteral, porém também dispõem de outros meios para sua disseminação. A Hepatite B por exemplo, é considerada uma Infecção Sexualmente Transmissível (IST), pois pode ser transmitida por via sexual. A transmissão também pode ocorrer de mãe para filho durante o parto ou por fluidos corporais como urina, saliva, sêmen, secreção vaginal e leite materno (BRASIL, 2018; GONÇALVES NV, et al. 2019a).

O quadro clinico da hepatite B pode se apresentar nas formas grave ou fulminante, no entanto é uma doença assintomática na maioria dos casos. A manifestação de sintomas inicia no período após a incubação podendo gerar fraqueza, anorexia, náuseas, desconforto abdominal, vômitos e icterícia. A fase crônica da hepatite B está entre a terceira e a quarta posição de causas de cirrose e acomete de $5 \%$ a $10 \%$ dos adultos infectados pelo HBV (PAULA VS, et al., 2015; BRASIL, 2018).

A hepatite $C$ pode ser transmitida através do sangue, o que pode ter levado a muitas infecções por meio de transfusão sanguínea antes de ser incluso o teste de detecção do anti-HCV. Após a inclusão da testagem nos bancos de sangue, houve um controle maior na transmissão da Hepatite $C$, limitando-a a outros tipos de transmissão, como por exemplo o compartilhamento de objetos perfuro cortantes como seringas e materiais de manicure, por infecção nosocomial ou por via sexual. (PAULA VS, et al., 2015; BRASIL, 2018).

Na hepatite C a maioria dos casos é assintomática. A fase crônica da hepatite C acomete de $70 \%$ a $85 \%$ dos indivíduos infectados e cerca de um terço pode evoluir para a forma grave ou cirrose ao longo de um período de 20 anos se não tratado (BRASIL, 2018). Alguns sintomas observados são náuseas, dor, fadiga e alguns podem apresentar icterícia. A hepatite $C$ é o maior responsável por casos de cirrose e transplante de fígado no ocidente (MACEDO TFS, et al., 2014; PAULA VS, et al., 2015; BRASIL, 2018). Ele leva ao agravamento do quadro de pessoas infectadas pelo vírus da hepatite B e é, segundo o Ministério da Saúde, responsável pela maioria dos casos de cirrose hepática em crianças e adultos jovens em áreas endêmicas na região amazônica do Brasil (BRASIL, 2018).

A infecção pelo HDV só pode se instalar mediante uma prévia infecção pelo HBV e sua evolução depende do contato inicial com o vírus, possuindo duas vertentes, sendo a superinfecção estado que ocorre quando $o$ indivíduo já possuía uma infecção crônica pelo vírus da HBV e posteriormente adquire o HDV. Neste caso se manifesta um quadro de hepatite aguda grave e que resulta em cronificação da hepatite $\mathrm{D}$ em $80 \%$ dos casos. Já na coinfecção o indivíduo é acometido pelos dois vírus ao mesmo tempo, mas neste caso a coinfecção é autolimitada, e menos de $5 \%$ dos indivíduos desenvolvem a forma crônica (PAULA VS, et al., 2015; BRASIL, 2018; COSTA PLS, 2020). 
Na Hepatite $D$ também há transmissão através do sangue e fluidos corpóreos. O vírus da hepatite $D$ é o vírus mais patogênico e infeccioso entre os hepatotrópicos, apesar de também ser o menos prevalente (MACEDO TFS, et al., 2014; PAULA VS, et al., 2015; BRASIL, 2018).

Dentre as principais medidas de prevenção podemos citar o controle em bancos de sangue através das análises laboratoriais, evitar o compartilhamento de objetos pessoais como toalhas, escovas de dente, seringas, e a utilização de preservativos durante 0 ato sexual. Em relação à prevenção por imunização, 0 ministério da saúde disponibiliza de forma gratuita a vacina contra o HBV, implementada no Brasil em 1992, está por sua vez também previne a infecção pelo HDV, visto que ele precisa que o paciente seja portador do HBV. Até o momento não existe vacina contra a hepatite $C$, que é tratada com medicamentos (MACEDO TFS, et al., 2014; PAULA VS et al., 2015; BRASIL, 2018).

As hepatites virais têm distribuição universal, mas variando de acordo com a região estudada. No Brasil a distribuição da doença se apresenta de forma diferente de região para região, tendo fatores como a extensão territorial brasileira, distribuição geográfica e os métodos de saneamento e controle de doenças tomados pelos estados e municípios (GONÇALVES NV, et al., 2019a; GONÇALVES NV, et al., 2019b; TIMÓTEO MVF, et al., 2020; MOTA ACC, et al., 2020).

Dessa forma o objetivo principal do estudo foi analisar e discutir os dados sobre as hepatites infectocontagiosas para melhor compreender o cenário dessas doenças no estado do Pará.

\section{MÉTODOS}

Para o desenvolvimento deste trabalho, foi realizado um estudo exploratório por meio de levantamento de dados dos Boletins Epidemiológico de Hepatites Virais do Departamento de Condições Crônicas e Infecções Sexualmente Transmissíveis do Ministério da Saúde do Brasil e do departamento de informática do Sistema Único de Saúde do Brasil (DATASUS). Em ambas foram extraídos dados das hepatites B, C e D.

Foram analisados no Boletim de Hepatites Virais - 2020 dados dos anos de 2009 a 2018, considerando casos confirmados e óbitos, além das taxas de incidência e mortalidade no estado do Pará. No DATASUS foram analisados os dados de Hepatites virais - Casos confirmados notificados no sistema de informação de agravos de notificação - Pará, no mesmo período, considerando os segmentos: Raça, sexo, faixa etária e mecanismos de infecção. Os dados foram tabelados no programa Microsoft Excel e convertidos em gráficos e tabelas para análise dos resultados obtidos.

Este trabalho não demandou envolvimento do Comitê de Ética em Pesquisa justificado pelo não uso de material biológico dos indivíduos pelos autores da pesquisa e pela não divulgação de seus dados pessoais.

\section{RESULTADOS E DISCUSSÃO}

De acordo com estudos feitos por autores como Aquino JA, et al., (2008), Ferreira CT e Silveira TR (2004) e Clemens SAC, et al., (2000), o Norte do Brasil apresenta maior endemicidade quanto as hepatites virais em relação ao restante do país, assim como uma maior taxa de mortalidade, apesar da desigualdade de notificação dos dados. Essa prevalência na região norte pode ser justificada pelas características socioeconômicas e demográficas da citada população. As maiores taxas de incidência das hepatites foram observadas em grupos de baixo nível socioeconômicos.

Dentre as hepatites a que apresenta a maior quantidade de casos confirmados no estado do Pará é a HBV, sendo seguida da HCV e por último a HDV. Somente em dois anos a HCV teve o número de casos confirmados maior que a da HBV, nos anos de 2010 e 2016 ( $n=263 ; n=302)$. Os maiores números de casos de HBV foram registrados nos anos de 2017 e 2018, com 351 e 338 casos, respectivamente. Indicando um aumento das infecções nos últimos anos. A quantidade de casos acumulados de HBV no período de 2009 a 2018 foram de 2.711. As maiores quantidades de casos de HCV foram registrados em 2016 e 2017, com 302 e 342 casos respectivamente (Figura 1A). 
Figura 1 - Número de casos confirmados e de óbitos Hepatite B, C e D no Pará nos anos de 2009 a 2018.

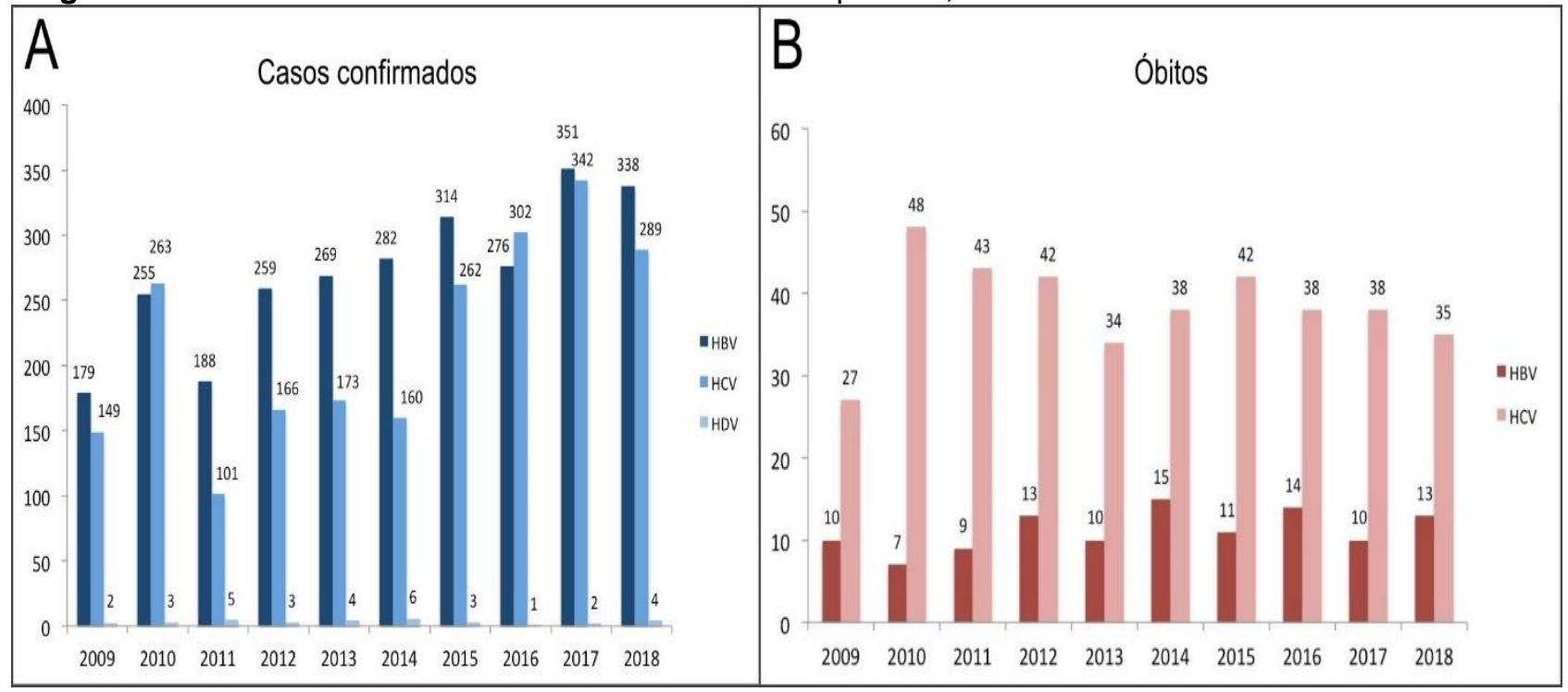

Legenda: HBV (Hepatitis B virus); HCV (Hepatitis C virus); HDV (Hepatitis D virus).

Fonte: Leão DV, et al., 2021; dados extraídos de Boletim de Hepatites Virais/2020. Ministério da Saúde do Brasil.

O número de casos confirmados de HDV são bem menores quando comparados com a HCV e HBV, principalmente devido ao fato que para se contaminar com a HDV, precisa-se ter contraído primeiro a HBV. Os maiores picos de casos de HDV confirmados foram nos anos de 2011 e 2014, com 5 e 6 casos respectivamente. Este fato pode estar relacionado à cobertura vacinal do tipo viral $\mathrm{B}$, pois com a disponibilidade das vacinas, a administração correta das doses do imunizante e o tratamento adequado, não há um desenvolvimento do quadro crônico da hepatite $B$, e por consequência não será criado um mecanismo de infecção pela hepatite D (ZORZETTO R, 2011).

Para o parâmetro quantidade de óbitos somente existiu registro de óbitos causado por infecções de HBV e HCV, não tendo, portanto, mortes por HDV. O número de mortes por HCV são superiores ao do HBV, sendo a quantidade três vezes maior em vários anos durante o período estudado. O número absoluto de óbitos por ano não variou muito para ambos os vírus como ilustrado na Figura 1B.

O total de óbitos por HBV entre 2009 e 2018 foi de 112 correspondendo a 4,13\% de óbitos sobre o total de casos confirmados no mesmo período $(n=2.711)$. A maior porcentagem de óbitos por HBV entre os casos confirmados no mesmo ano foi em 2009, com 5,58\%, onde existiu 10 óbitos e 179 casos confirmados. Referentes ao HCV, o número total de óbitos entre 2009 e 2018 foi de 385 correspondendo a 17,44\% do total de casos confirmados $(n=2.208)$. Dentro os anos, o que apresentou maior porcentagem de mortalidade foi o de 2011, com 42,57\%. Essa alta porcentagem é devido à neste ano a quantidade de casos confirmados terem sidos bem menores que os outros anos e manteve o número de óbitos semelhante ao dos outros anos.

Os elevados números de casos das hepatites $\mathrm{B}$ e $\mathrm{C}$ no território paraense estão relacionados a vários fatores, dentre eles, segundo Gonçalves NV, et al., (2019b) a associação da infecção das hepatites com a ocorrência de doenças sexualmente transmissíveis e o modo como cada município desenvolve ações de políticas públicas voltadas para a promoção da saúde, como campanhas educativas que impactem diretamente na diminuição da quantidade desses casos associados.

A incidência mostra a velocidade que novos casos de uma doença acontecem em uma determinada população, considerando o tempo em que as pessoas estão livres da doença, portanto, tendo o risco de desenvolve-la (BONITA R, 2005). Para expressar de forma mais precisa esses dados, Last JM (2001) desenvolveu uma fórmula onde podemos calcular a "taxa de incidência". Para os cálculos são considerados o número de casos confirmados em um período e local como numerador e a população total no mesmo 
período e local como denominador, ainda multiplicado por um fator conforme fórmula, número de casos de hepatite confirmados em um determinado ano de notificação e local de residência dividido pela população total no mesmo ano, residente no mesmo local vezes 100.000 .

A taxa de incidência das hepatites B e C calculadas pelo Ministério da Saúde utiliza um fator de 100.000, o que indica a taxa de novos casos a cada 100 mil habitantes. Essas taxas são fundamentais, porque com elas podemos comparar a incidência do estado do Pará com a de outros estados do Brasil e analisar como se encontra a propagação da doença, podendo dessa forma criar estratégias de prevenção.

Com base nos dados do Boletim de Hepatites Virais - 2020, a taxa de incidência do HBV e HCV no Pará tem aumentado de 2009 a 2018. Em poucos anos, observa-se a queda na taxa de incidência de ambos os vírus, como em 2011 e 2018. O número de novos casos de HBV são superiores em praticamente em todos os anos ao de HCV, entretanto existe um grande aumento de novos casos de HCV, esses ficando quase iguais ou superiores ao do HBV entre os anos de 2015 a 2018. No período de 10 anos a taxa de HBV aumentou de 2,4 para 4 e a de HCV de 2 para 3,4, evidenciando que os números de novos casos no estado têm aumentando ao longo do tempo (Figura 2).

Figura 2 - Taxa de incidência (detecção) por Hepatite B e C no Pará nos anos de 2009 a 2018 por 100.000 habitantes.

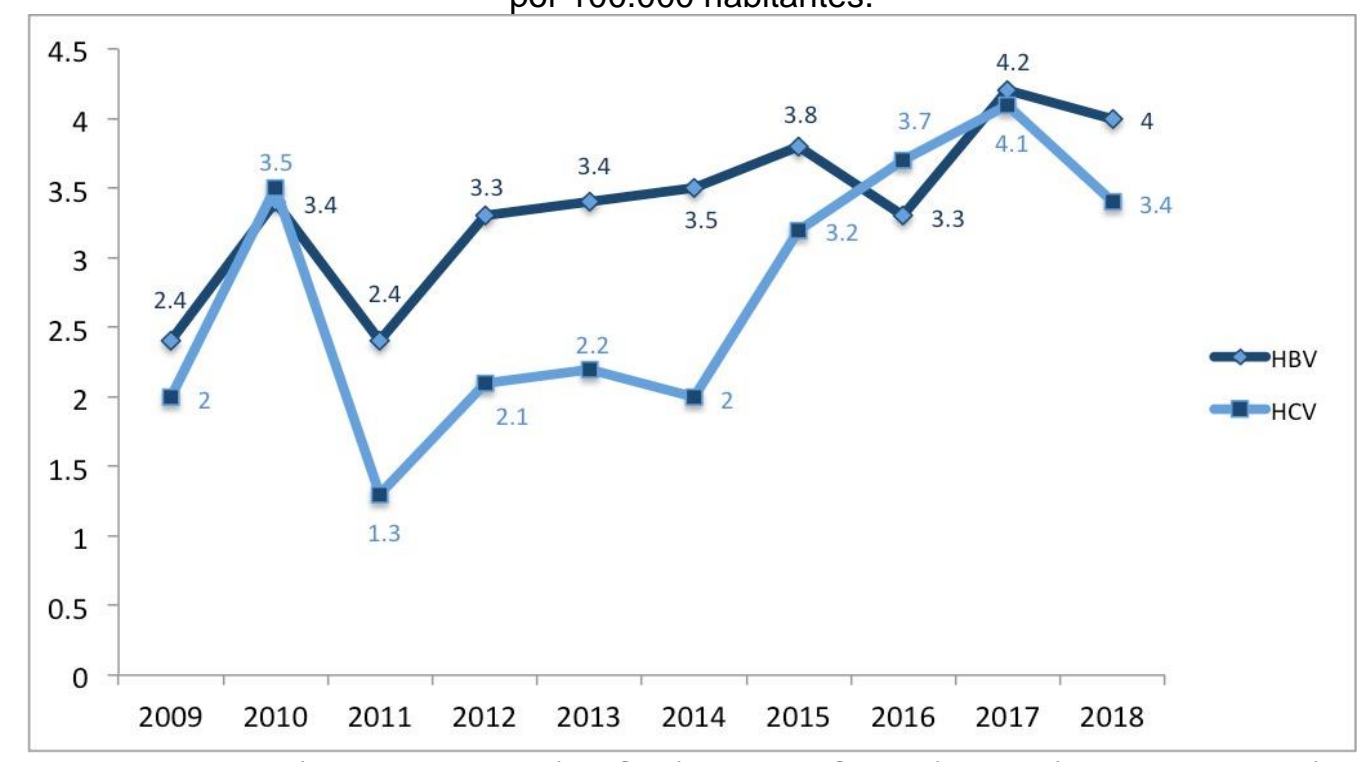

Legenda: HBV (Hepatitis B virus); HCV (Hepatitis C virus); HDV (Hepatitis D virus). Fonte: Leão DV, et al., 2021; dados extraídos de Boletim de Hepatites Virais/2020. Ministério da Saúde do Brasil.

As taxas de detecção da hepatite $C$ no Estado do Pará acompanham o cenário nacional, pois houve uma tendência de crescimento entre 2003 e 2016, devido à disponibilidade de métodos diagnósticos com marcadores anti - HCV e HCV - RNA reagentes, métodos estes que tornaram o diagnóstico das hepatites mais preciso (BELOQUI JA, 2017). Aliado a esta tendência nacional temos também o Ministério da Saúde instituindo no Brasil a ação da Campanha do Dia Mundial de Luta contra as Hepatites Virais, em 2015, onde é incentivado o aconselhamento e testagem das pessoas, para possível diagnóstico, controle e/ou tratamento (BRASIL, 2020).

Assim como a incidência a mortalidade também pode ser transformado em uma taxa, sendo nesse caso a 'taxa de mortalidade' usada para medir o risco de óbito em consequência de uma hepatite na população geral. O cálculo da taxa de mortalidade é semelhante ao da taxa de incidência, são considerados o número de óbitos em um período e local como numerador e a população residente no mesmo período e local como denominador, multiplicado por um fator conforme fórmula, número de óbitos por hepatite em um determinado ano e local de residência dividido pela população de residentes no mesmo local, no mesmo ano vezes 100.000 . 
A taxa de mortalidade das hepatites B e C no estado do Pará entre os anos de 2009 a 2018 indica o risco de óbito para cada 100 mil habitantes. A taxa de mortalidade por HBV se manteve estável, flutuando entre 0,1 e 0,2 ao longo de 2009 a 2018. Já nos casos de HCV a taxa de mortalidade aumentou nos anos de 2010 e $2011(0,6)$ com queda nos dois anos seguintes e posteriormente sem muitas variações. Durante o período de 2009 a 2018, a taxa inicial era de 0,4 chegou ao máximo 0,6 e depois diminui para 0,5 e em 2018 retornando para 0,4. O número de óbitos por HCV é mais elevado que os causados pelo HBV, apesar da incidência do HBV ser maior. As taxas de mortalidades apresentam menos variações quando comparadas com as taxas de incidência, mostrando que apesar de o número de novos casos aumentarem, o risco de as pessoas morrerem por essas infecções virais não aumentou (Figura 3).

Figura 3 - Taxa de mortalidade por Hepatite B e C no Pará nos anos de 2009 a 2018 por 100.000 habitantes.

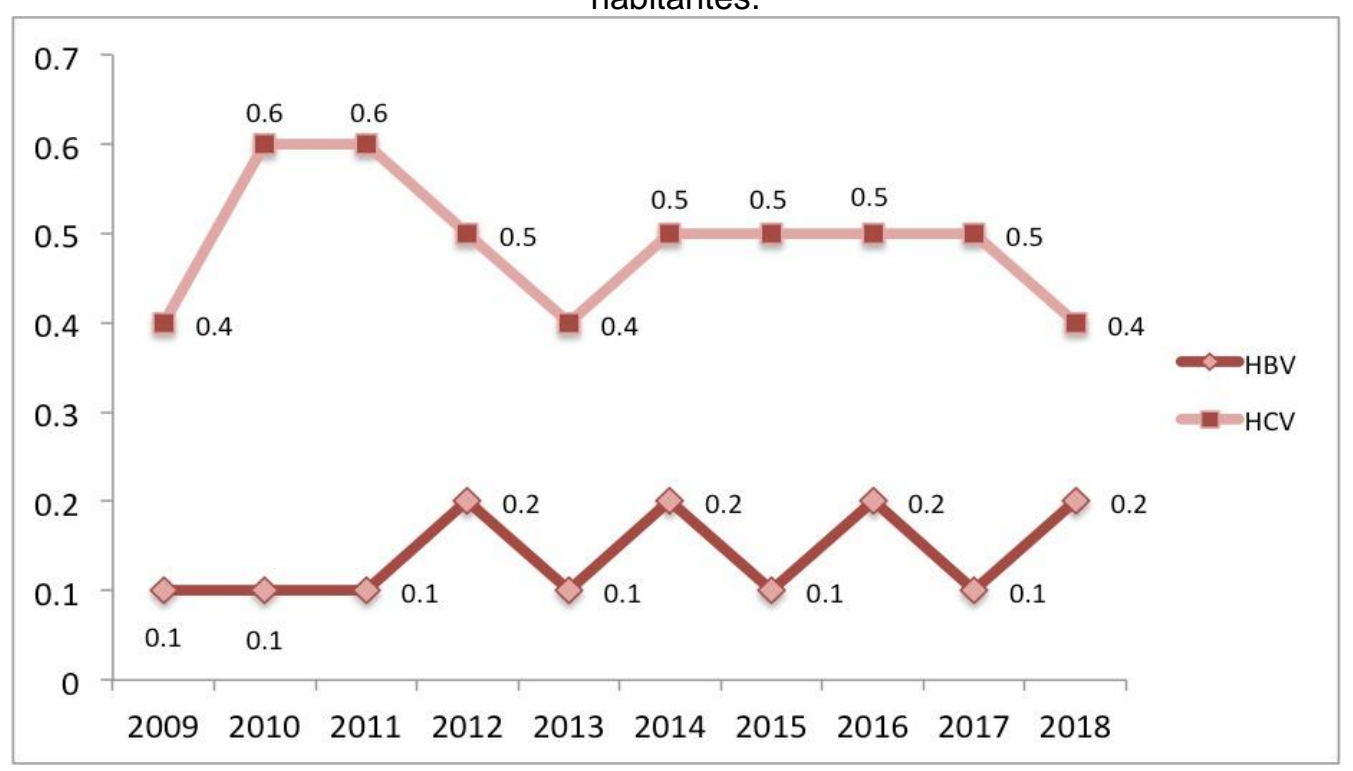

Legenda: HBV (Hepatitis B virus); HCV (Hepatitis C virus); HDV (Hepatitis D virus).

Fonte: Leão DV, et al., 2021; dados extraídos de Boletim de Hepatites Virais/2020. Ministério da Saúde do Brasil.

$\mathrm{O}$ fato de a taxa de mortalidade por HCV ser maior que por HBV, mesmo a hepatite $B$ sendo mais incidente pode ser explicado, segundo Paula VS, et al. (2015) e dados do Ministério da saúde (2018), por cerca de 90 a $95 \%$ dos adultos infectados pelo HBV evoluírem para a cura espontânea, e apenas um número menor que $1 \%$ venha a desenvolver hepatite fulminante. Ademais, a hepatite $B$ já está inserida no programa Nacional de imunização, tendo sua eficácia comprovada através de estudos, que resultam em uma boa imunogenicidade conferida após administrada (SÃO PAULO, 2006) e dispõe de dois tratamentos para indivíduos já infectados: interferon e antivirais. Diferente do HBV, o HCV apesar de apresentar menor taxa de infectividade, leva a uma infecção assintomática e persistente em cerca de $80 \%$ dos pacientes, podendo sem tratamento, evoluir para um quadro de cirrose e carcinoma hepatocelular. (PAULA VS, et al., 2015; BRASIL, 2018).

Outros dados analisados foram a quantidade de indivíduos infectados por raça, sexo, faixa etária e mecanismos de infecção. Tais dados foram retirados do DATASUS, e em todos nota-se a disparidade da incidência da Hepatite $D$ quando comparadas com a hepatites B e C. A hepatite D apesar de mais infecciosa é a menos prevalente, aparecendo em pouquíssimos casos. Um dos motivos pode ser o fato de que ele necessita de uma pré infecção pelo HBV, que já possui vacinação disponível nos postos de saúde, sendo a maneira mais eficaz de prevenir a infecção por HDV, considerando que este meio reduz o número de pessoas que podem vir a contrair ambas as doenças, tanto em casos de coinfecção entre as hepatites $B$ e $D$ como em casos de superinfecção.

No segmento faixa etária observa-se que a maior incidência de infecções pelas hepatites infectocontagiosas se deu nas faixas etárias de 20 a 39 e de 40 a 59 anos, com maiores picos nos anos de 2015 e 2017 (Tabela 1). 
Tabela 1 - Casos confirmados de Hepatite B, C e D segundo faixas etárias entre os anos de 2009 a 2018.

\begin{tabular}{|c|c|c|c|c|c|c|c|c|c|c|c|}
\hline & \multicolumn{11}{|c|}{ ANO } \\
\hline & Faixa Etária & 2009 & 2010 & 2011 & 2012 & 2013 & 2014 & 2015 & 2016 & 2017 & 2018 \\
\hline \multirow{12}{*}{ HBV } & Ign/Branco & 1 & 0 & 0 & 0 & 0 & 0 & 0 & 0 & 0 & 0 \\
\hline & $<1$ Ano & 1 & 1 & 4 & 1 & 1 & 4 & 7 & 4 & 4 & 2 \\
\hline & 1 a 4 & 1 & 0 & 1 & 2 & 1 & 2 & 2 & 1 & 0 & 2 \\
\hline & 5 a 9 & 0 & 1 & 0 & 1 & 2 & 1 & 1 & 2 & 0 & 1 \\
\hline & 10 a 14 & 1 & 1 & 3 & 4 & 6 & 3 & 3 & 2 & 0 & 0 \\
\hline & 15 a 19 & 7 & 10 & 20 & 28 & 19 & 32 & 15 & 17 & 20 & 6 \\
\hline & 20 a 39 & 77 & 98 & 77 & 117 & 178 & 181 & 196 & 157 & 223 & 159 \\
\hline & 40 a 59 & 40 & 64 & 29 & 51 & 111 & 120 & 131 & 133 & 142 & 101 \\
\hline & 60 a 64 & 3 & 7 & 10 & 4 & 12 & 15 & 11 & 34 & 19 & 9 \\
\hline & 65 a 69 & 1 & 9 & 3 & 5 & 13 & 13 & 16 & 17 & 13 & 11 \\
\hline & 70 a 79 & 2 & 3 & 2 & 4 & 8 & 14 & 15 & 16 & 18 & 8 \\
\hline & $80 e+$ & 1 & 1 & 0 & 0 & 2 & 4 & 5 & 2 & 2 & 3 \\
\hline \multirow{12}{*}{$\mathrm{HCV}$} & Ign/Branco & 0 & 0 & 0 & 0 & 0 & 0 & 0 & 0 & 0 & 0 \\
\hline & $<1$ Ano & 2 & 2 & 0 & 2 & 3 & 0 & 9 & 4 & 2 & 3 \\
\hline & 1 a 4 & 0 & 0 & 1 & 0 & 0 & 0 & 1 & 0 & 0 & 0 \\
\hline & 5 a 9 & 0 & 2 & 0 & 1 & 0 & 0 & 0 & 0 & 0 & 0 \\
\hline & 10 a 14 & 1 & 3 & 0 & 0 & 1 & 1 & 2 & 5 & 1 & 0 \\
\hline & 15 a 19 & 0 & 5 & 3 & 4 & 1 & 1 & 3 & 2 & 4 & 2 \\
\hline & 20 a 39 & 23 & 31 & 14 & 16 & 17 & 24 & 43 & 41 & 61 & 24 \\
\hline & 40 a 59 & 48 & 83 & 45 & 66 & 88 & 74 & 132 & 159 & 179 & 84 \\
\hline & 60 a 64 & 12 & 17 & 5 & 17 & 20 & 24 & 32 & 50 & 54 & 28 \\
\hline & 65 a 69 & 10 & 11 & 4 & 12 & 13 & 11 & 13 & 41 & 36 & 10 \\
\hline & 70 a 79 & 4 & 7 & 4 & 6 & 7 & 4 & 13 & 19 & 27 & 15 \\
\hline & $80 e+$ & 2 & 3 & 0 & 1 & 0 & 0 & 3 & 8 & 4 & 4 \\
\hline \multirow{12}{*}{ HDV } & Ign/Branco & 0 & 0 & 0 & 0 & 0 & 0 & 0 & 0 & 0 & 0 \\
\hline & $<1$ Ano & 0 & 0 & 0 & 0 & 0 & 0 & 0 & 0 & 0 & 0 \\
\hline & 1 a 4 & 0 & 0 & 0 & 0 & 0 & 0 & 0 & 0 & 0 & 0 \\
\hline & 5 a 9 & 0 & 0 & 0 & 0 & 0 & 0 & 0 & 0 & 0 & 0 \\
\hline & 10 a 14 & 0 & 0 & 0 & 2 & 0 & 0 & 0 & 0 & 0 & 0 \\
\hline & 15 a 19 & 0 & 0 & 1 & 0 & 0 & 0 & 0 & 0 & 0 & 0 \\
\hline & 20 a 39 & 0 & 0 & 0 & 0 & 2 & 0 & 0 & 0 & 0 & 1 \\
\hline & 40 a 59 & 1 & 1 & 0 & 0 & 0 & 0 & 1 & 1 & 0 & 2 \\
\hline & 60 a 64 & 0 & 0 & 0 & 0 & 0 & 0 & 0 & 0 & 1 & 0 \\
\hline & 65 a 69 & 0 & 0 & 0 & 0 & 0 & 0 & 0 & 0 & 0 & 0 \\
\hline & 70 a 79 & 0 & 0 & 0 & 0 & 0 & 0 & 0 & 0 & 0 & 0 \\
\hline & $80 e+$ & 0 & 0 & 0 & 0 & 0 & 0 & 0 & 0 & 0 & 0 \\
\hline
\end{tabular}

Legenda: HBV (Hepatitis B virus); HCV (Hepatitis C virus); HDV (Hepatitis D virus). Fonte: Leão DV, et al., 2021; dados extraídos de Departamento de Informática do Sistema Unico de Saúde do Brasil (DATASUS).

A idade entre 20 e 39 anos é a mais atingida pela HBV, enquanto que a idade entre 40 e 59 foram mais prevalentes a HCV e HDV. A prevalência nesta faixa etária pode estar associada a cobertura vacinal, pois a vacina alcança a faixa etária até aos 29 anos de idade, deixando indivíduos na faixa entre os 30 e 59 anos mais vulneráveis a estas infecções (CRUZ AS, 2016). Já os casos dentre a faixa etária de 0 a 1 ano são comuns devido a transmissão vertical, onde se há a transmissão placentária de mãe para filho e à pobreza de informação e acesso à saúde para acompanhamento pré-natal disponibilizado pelo Sistema Único De Saúde (SUS) (GARDENAL RVC, et al., 2011).

No segmento "raça" observa-se a predominância maior em indivíduos pardos, com expressivo aumento nos números de casos entre os anos de 2009 com 88 casos por HBV e 58 por HCV e 2017 com 375 casos por HBV e 309 por HCV. A hepatite $D$ também se mostrou prevalente em pardos, porém ainda com um número reduzido de casos, com apenas 10 notificações entre 2009 e 2018 como mostra a Tabela 2. 
Tabela 2 - Casos confirmados de Hepatite B segundo raças e sexo, entre os anos de 2009 a 2018.

\begin{tabular}{|c|c|c|c|c|c|c|c|c|c|c|c|}
\hline & \multicolumn{11}{|c|}{ ANO } \\
\hline & RAÇAS & 2009 & 2010 & 2011 & 2012 & 2013 & 2014 & 2015 & 2016 & 2017 & 2018 \\
\hline \multirow{6}{*}{ HBV } & Ign/Branco & 9 & 14 & 4 & 2 & 22 & 51 & 36 & 22 & 3 & 1 \\
\hline & Branca & 13 & 16 & 12 & 13 & 33 & 26 & 29 & 21 & 26 & 19 \\
\hline & Preta & 6 & 11 & 13 & 13 & 31 & 23 & 26 & 18 & 31 & 22 \\
\hline & Amarela & 0 & 1 & 0 & 1 & 1 & 0 & 0 & 2 & 2 & 2 \\
\hline & Parda & 108 & 153 & 120 & 187 & 243 & 278 & 305 & 321 & 375 & 245 \\
\hline & Indígena & 0 & 0 & 0 & 1 & 23 & 11 & 6 & 1 & 4 & 13 \\
\hline \multirow{6}{*}{ HCV } & Ign/Branco & 12 & 42 & 2 & 10 & 18 & 11 & 15 & 11 & 2 & 7 \\
\hline & Branca & 9 & 16 & 9 & 6 & 20 & 12 & 14 & 20 & 29 & 19 \\
\hline & Preta & 3 & 3 & 1 & 3 & 6 & 2 & 15 & 13 & 26 & 10 \\
\hline & Amarela & 2 & 0 & 1 & 0 & 0 & 0 & 1 & 3 & 0 & 1 \\
\hline & Parda & 76 & 103 & 63 & 106 & 105 & 114 & 204 & 282 & 309 & 132 \\
\hline & Indígena & 0 & 0 & 0 & 0 & 1 & 0 & 2 & 0 & 2 & 1 \\
\hline \multirow{6}{*}{ HDV } & Ign/Branco & 1 & 0 & 0 & 2 & 0 & 0 & 0 & 0 & 0 & 0 \\
\hline & Branca & 0 & 0 & 0 & 0 & 0 & 0 & 0 & 0 & 0 & 0 \\
\hline & Preta & 0 & 0 & 0 & 0 & 0 & 0 & 0 & 0 & 0 & 0 \\
\hline & Amarela & 0 & 0 & 0 & 0 & 0 & 0 & 0 & 0 & 0 & 0 \\
\hline & Parda & 0 & 1 & 1 & 0 & 2 & 0 & 1 & 1 & 1 & 3 \\
\hline & Indígena & 0 & 0 & 0 & 0 & 0 & 0 & 0 & 0 & 0 & 0 \\
\hline \multicolumn{12}{|c|}{ SEXO } \\
\hline \multirow{2}{*}{ HBV } & Masc & 70 & 107 & 68 & 85 & 176 & 180 & 204 & 195 & 220 & 153 \\
\hline & Fem & 66 & 88 & 81 & 132 & 177 & 209 & 198 & 190 & 221 & 149 \\
\hline \multirow{2}{*}{$\mathrm{HCV}$} & Masc & 54 & 106 & 41 & 61 & 76 & 180 & 134 & 191 & 203 & 90 \\
\hline & Fem & 48 & 58 & 35 & 64 & 74 & 58 & 117 & 138 & 165 & 80 \\
\hline \multirow{2}{*}{ HDV } & Masc & 0 & 1 & 1 & 2 & 1 & 0 & 0 & 0 & 0 & 2 \\
\hline & Fem & 1 & 0 & 0 & 0 & 1 & 0 & 1 & 1 & 1 & 1 \\
\hline
\end{tabular}

Legenda: HBV (Hepatitis B virus); HCV (Hepatitis C virus); HDV (Hepatitis D virus). Masc (Masculino); Fem

(Feminino). Fonte: Leão DV, et al., 2021; dados extraídos de Departamento de Informática do Sistema Único de Saúde do Brasil (DATASUS).

O elevado número de pardos infectados pode estar relacionado à própria característica da população no Brasil. A Pesquisa Nacional por Amostra de Domicílios Contínua (PNAD) relativa a 2012/2019 informa que a população brasileira é composta por $46,8 \%$ de pessoas autodeclaradas pardas, seguida da população declarada branca $(42,7 \%)$. Fatos estes que corroboram com os estudos aplicados no levantamento da prevalência das hepatites notificadas que ocorreram nessa população, no período relacionado (2009 a 2018) (IBGE, 2010). Estudo conduzido por Chor D e Lima CRA (2005) também correlacionou as raças com a distribuição da epidemiologia das doenças, discorrendo sobre às desigualdades raciais e sociais aonde estão inseridas. Segundo o autor essas desigualdades têm como consequência um alto risco acarretar enfermidades às populações marginalizadas, em decorrência da situação social, econômica e sanitária aonde essa população se encontra, sendo submetidas a situações de risco por viverem em conjuntura de higiene precária, baixo acesso aos cuidados à saúde e possível exposição a agentes tóxicos no meio.

Já no segmento "sexo", ainda na Tabela 2, é possível observar que os vírus HBV e HCV não apresentaram grande diferença na incidência entre os gêneros masculino e feminino. No entanto o HCV é mais prevalente nos homens, quando comparados ao sexo feminino.

Segundo estudos feitos por Dias JA, et al. (2014), este fato pode decorrer de os homens apresentarem mais fatores de risco associados à transmissão de determinados tipos de vírus da hepatite, ocasionado pelo menor uso de preservativo, maior quantidade de parceiras (os) sexuais e maior uso de drogas ilícitas que demandaram uso de meios que podem ser tornar via de transmissão. Um outro estudo realizado no estado 
do Pará por Aquino JA, et al. (2008), possui dados que corroboram com à maior prevalência sorológica em homens. Segundo o estudo, dos casos notificados, $62,6 \%$ envolveram pessoas do sexo masculino, indicando que devido ao comportamento sexual, eles podem estar mais expostos, além de que prevalência pode também ser explicada pelos indivíduos do sexo masculino estarem em maior número trabalhando na área da saúde. As maiores discrepâncias estão nos anos de 2010, 2014 e 2016, com diferença de 48, 95 e 53 casos respectivamente entre os gêneros.

É possível notar falta de notificação em relação aos mecanismos de infecção em $63,31 \%$ dos casos informados na Tabela 3, identificados como dado ignorado (Ign/Branco).

Tabela 3 - Casos confirmados de Hepatite B, C e D segundo mecanismos de infecção entre os anos de 2009 a 2018.

\begin{tabular}{|c|c|c|c|c|c|c|c|c|c|c|c|}
\hline & & & & & & ANO & & & & & \\
\hline & Formas de Infecção & 2009 & 2010 & 2011 & 2012 & 2013 & 2014 & 2015 & 2016 & 2017 & 2018 \\
\hline \multirow{13}{*}{ HBV } & Ign/Branco & 90 & 88 & 94 & 174 & 193 & 276 & 244 & 225 & 214 & 124 \\
\hline & Sexual & 27 & 44 & 38 & 24 & 121 & 68 & 104 & 119 & 154 & 115 \\
\hline & Transfusional & 3 & 5 & 2 & 1 & 3 & 1 & 6 & 1 & 2 & 4 \\
\hline & Drogas injetáveis & 0 & 2 & 1 & 0 & 1 & 0 & 0 & 0 & 1 & 1 \\
\hline & Vertical & 3 & 7 & 2 & 1 & 1 & 3 & 1 & 2 & 1 & 3 \\
\hline & Acidente de trabalho & 0 & 0 & 0 & 0 & 2 & 1 & 0 & 0 & 0 & 0 \\
\hline & Hemodiálise & 0 & 2 & 0 & 0 & 2 & 1 & 0 & 1 & 0 & 0 \\
\hline & Domiciliar & 1 & 36 & 0 & 3 & 8 & 2 & 4 & 4 & 5 & 2 \\
\hline & Tratamento cirúrgico & 0 & 1 & 1 & 1 & 1 & 3 & 3 & 1 & 3 & 0 \\
\hline & Tratamento dentário & 1 & 4 & 1 & 2 & 4 & 8 & 13 & 4 & 6 & 2 \\
\hline & Pessoa/pessoa & 2 & 1 & 1 & 2 & 9 & 5 & 0 & 2 & 3 & 1 \\
\hline & Alimento/água & 1 & 1 & 1 & 3 & 2 & 4 & 5 & 2 & 5 & 1 \\
\hline & Outros & 8 & 4 & 8 & 6 & 6 & 17 & 22 & 24 & 47 & 49 \\
\hline \multirow{13}{*}{$\mathrm{HCV}$} & Ign/Branco & 72 & 118 & 51 & 104 & 193 & 104 & 150 & 268 & 289 & 104 \\
\hline & Sexual & 11 & 11 & 12 & 12 & 121 & 21 & 42 & 37 & 4 & 29 \\
\hline & Transfusional & 2 & 10 & 2 & 0 & 3 & 0 & 12 & 4 & 4 & 3 \\
\hline & Drogas injetáveis & 5 & 3 & 3 & 4 & 1 & 2 & 3 & 5 & 2 & 2 \\
\hline & Vertical & 0 & 0 & 0 & 1 & 1 & 0 & 0 & 0 & 0 & 1 \\
\hline & Acidente de trabalho & 1 & 0 & 1 & 0 & 2 & 0 & 2 & 1 & 0 & 0 \\
\hline & Hemodiálise & 0 & 1 & 0 & 0 & 2 & 1 & 0 & 0 & 0 & 0 \\
\hline & Domiciliar & 1 & 11 & 0 & 0 & 8 & 0 & 3 & 0 & 1 & 0 \\
\hline & Tratamento cirúrgico & 0 & 5 & 1 & 0 & 1 & 1 & 4 & 1 & 0 & 1 \\
\hline & Tratamento dentário & 4 & 1 & 1 & 0 & 4 & 4 & 16 & 1 & 4 & 9 \\
\hline & Pessoa/pessoa & 0 & 1 & 0 & 1 & 9 & 1 & 2 & 0 & 0 & 1 \\
\hline & Alimento/água & 0 & 0 & 0 & 0 & 2 & 0 & 3 & 2 & 2 & 0 \\
\hline & Outros & 6 & 3 & 5 & 3 & 6 & 5 & 14 & 10 & 21 & 20 \\
\hline \multirow{13}{*}{ HDV } & Ign/Branco & 0 & 0 & 0 & 0 & 0 & 0 & 0 & 0 & 1 & 1 \\
\hline & Sexual & 0 & 0 & 1 & 0 & 0 & 0 & 0 & 1 & 0 & 2 \\
\hline & Transfusional & 0 & 0 & 0 & 0 & 0 & 0 & 0 & 0 & 0 & 0 \\
\hline & Drogas injetáveis & 0 & 0 & 0 & 0 & 0 & 0 & 0 & 0 & 0 & 0 \\
\hline & Vertical & 0 & 1 & 0 & 0 & 0 & 0 & 0 & 0 & 0 & 0 \\
\hline & Acidente de trabalho & 0 & 0 & 0 & 0 & 0 & 0 & 0 & 0 & 0 & 0 \\
\hline & Hemodiálise & 0 & 0 & 0 & 0 & 0 & 0 & 0 & 0 & 0 & 0 \\
\hline & Domiciliar & 0 & 0 & 0 & 0 & 0 & 0 & 0 & 0 & 0 & 0 \\
\hline & Tratamento cirúrgico & 0 & 0 & 0 & 0 & 0 & 0 & 1 & 0 & 0 & 0 \\
\hline & Tratamento dentário & 0 & 0 & 0 & 0 & 0 & 0 & 0 & 0 & 0 & 0 \\
\hline & Pessoa/pessoa & 0 & 0 & 0 & 0 & 0 & 0 & 0 & 0 & 0 & 0 \\
\hline & Alimento/água & 1 & 0 & 0 & 2 & 2 & 0 & 0 & 0 & 0 & 0 \\
\hline & Outros & 0 & 0 & 0 & 0 & 0 & 0 & 0 & 0 & 0 & 0 \\
\hline
\end{tabular}

Legenda: HBV (Hepatitis B virus); HCV (Hepatitis C virus); HDV (Hepatitis D virus). Fonte: Leão DV, et al., 2021; dados extraídos de Departamento de Informática do Sistema Único de Saúde do Brasil (DATASUS). 
A Falta de notificação ou conhecimento quanto ao mecanismo que levou à infecção dos indivíduos interfere na análise final, deixando os dados incompletos. Dos mecanismos identificados, o que apresentou maior expressão foi o sexual, com $27,15 \%$ dos casos totais em HBV e $14,62 \%$ em HCV. Já em HDV o mecanismo predominante foi por alimento/água $(38,46 \%)$ seguido pelo sexual $(30,76 \%)$. Também se destacaram como fonte de infecção as vias domiciliares, por tratamento dentário e transfusional.

Há controvérsias quanto a atuação da via sexual em relação a hepatite C. Segundo Klevens MR, et al. (2012) e Paula VS, et al. (2015) grande parte da literatura afirma que a taxa de transmissão de hepatite C pela via sexual é baixa. No entanto segundo o Ministério da Saúde (2018) e Macedo TFS, et al. (2014) o risco se eleva em indivíduos com múltiplos parceiros e que praticam o ato sexual sem preservativo. Um outro agravante citado pelos autores seria a coexistência de alguma IST como o HIV (Human Immunodeficiency Virus). Já a hepatite B é considerada fundamentalmente uma IST, dispondo dos mesmos agravantes da hepatite $\mathrm{C}$ assim como a D (BRASIL, 2018).

\section{CONCLUSÃO}

Através dos estudos epidemiológicos, conclui-se que a transmissão das hepatites virais no estado do Pará continua aumentando ao longo do tempo, mesmo com vacinação e tratamentos disponíveis, revelando a necessidade de desenvolvimento de ações públicas e educativas, que alcancem com facilidade toda a população afim de conscientiza-las das doenças a que podem se expor, as formas de exposição, além das formas de prevenção e tratamento disponíveis. São necessárias medidas para diminuir a quantidade de pessoas infectadas, principalmente nos grupos mais afetados como os pardos, pessoas com idade entre 20 e 59 anos e pessoas sujeitas contrair a infecção por via sexual.

\section{REFERÊNCIAS}

1. AQUINO JA, et al. Soroprevalência de infecções por vírus da hepatite $B$ e vírus da hepatite $C$ em indivíduos do Estado do Pará. Rev Soc Bras Med Trop, 2008; 41(4): 334-77.

2. BELOQUI JA. Alguns dados sobre a situação da Hepatite $C$ no Brasil para ativistas de HIV/AIDS. 2017. GIV - Grupo de incentivo à vida. São Paulo. Disponível em: http://www.giv.org.br/Arquivo/Folheto_GIV_HepatiteC_no_Brasil.pdf. Acessado em: 04/02/2021.

3. BONITA R, et al. Epidemiologia básica. [tradução e revisão científica Juraci A. Cesar]. - 2.ed. - São Paulo, Santos. 2010.

4. BRASIL. Ministério da saúde. Departamento de Doenças de condições crônicas e infecções sexualmente transmissíveis. Hepatites virais: histórico das ações. Brasília. 2020. Disponível em: http://www.aids.gov.br/pt$\mathrm{br} /$ hepatites-virais-evolucao-das-acoes. Acessado em: 05 de fevereiro de 2021.

5. BRASIL. Boletim Epidemiológico de Hepatites Virais. Ministério da saúde. Secretaria de vigilância em saúde. Departamento de doenças e condições crônicas e infecções sexualmente transmissíveis. 2020. Disponível em: http://www.aids.gov.br/pt-br/pub/2020/boletim-epidemiologico-hepatites-virais-2020. Acessado em: 07 de dezembro de 2020.

6. BRASIL. Casos confirmados por fonte de mecanismo de infecção segundo classificação etiológica. Ministério da saúde. DATASUS. Disponível em: http://tabnet.datasus.gov.br/cgi/tabcgi.exe?sinannet/cnv/hepapa.de. Acessado em: 09 de jan. de 2021.

7. BRASIL. Manual técnico para o diagnóstico das hepatites virais. Ministério da saúde (BR). Secretaria de vigilância em saúde. Departamento de ist, aids e hepatites virais. 2018. Disponível em: http://www.aids.gov.br/ptbr/pub/2015/manual-tecnico-para-o-diagnostico-das-hepatites-virais. Acessado em: 10 de dezembro de 2020.

8. CHOR D, LIMA CRA. Aspectos epidemiológicos das desigualdades raciais em saúde no Brasil. Cadernos de Saúde Pública, 2005; 21: 1586-1594.

9. CLEMENS SAC, et al. Hepatitis A and hepatitis B seroprevalence in four centers in Brazil. Revista da Sociedade Brasileira de Medicina Tropical, 2000; 33: 1.

10. COSTA PLS, et al. Coinfecção da Hepatite B e Delta na Amazônia: Artigo de atualização. Revista Eletrônica Acervo Saúde, 2020; 41: e1421.

11. CRUZ AS, et al. Levantamento de dados entre o período de 2010 a 2016 de Hepatite B no Município de Rolim de Moura. Brazilian Journal of Surgery and Clinical Research (BJSCR), 2018; 2317-4404.

12. DIAS JA, et al. Fatores associados à infecção pelo vírus da hepatite $B$ : um estudo caso-controle no município de São Mateus, Espírito Santo. Epidemiologia e Serviços de Saúde, 2014; 23: 683-690, 2014.

13. EXPASY. Viralzone. Deltavirus. Geneva: SIB Swiss Institute of Bioinformatics. 2019 Disponível em: https://viralzone.expasy.org/175. Acesso em: 9 jan. 2021.

14. EXPASY. Viralzone. Flaviviridae. Geneva: SIB Swiss Institute of Bioinformatics. 2019. Disponível em: <https://viralzone.expasy.org/43. Acesso em: 9 jan. 2021. 
15. EXPASY. Viralzone. Hepadnaviridae. Geneva: SIB Swiss Institute of Bioinformatics. 2019. Disponível em: https://viralzone.expasy.org/9. Acesso em: 9 jan. 2021.

16. FERREIRA CT, SILVEIRA TR. Hepatites virais: aspectos da epidemiologia e da prevenção. Revista Brasileira de epidemiologia, 2004; 7(4): 473-487.

17. GARDENAL RVC, et al. Hepatite $C$ e gestação: análise de fatores associados à transmissão vertical. Revista da Sociedade Brasileira de Medicina Tropical, 2011; 44(1): 43-47.

18. GONÇALVES NV, et al. Análise espacial e epidemiológica de hepatites B e $C$ e índice de desenvolvimento humano municipal, no estado do pará. Hygeia-Revista Brasileira de Geografia Médica e da Saúde, 2019b; 15(31): 29-42.

19. GONÇALVES NV, et al. Hepatites B e C nas áreas de três Centros Regionais de Saúde do Estado do Pará, Brasil: uma análise espacial, epidemiológica e socioeconômica. Cadernos Saúde Coletiva, 2019a; 27(1): 1-10.

20. IBGE. Instituto Brasileiro de geografia e Estatística. Censo demográfico, 2010; 2010.

21. KLEVENS RM, et al. Evolving epidemiology of hepatitis C virus in the United States. Clin Infect Dis, $2012 ; 55$ Suppl 1:S3-9.

22. LAST JM. A dictionary of epidemiology. 4th ed. Oxford, Oxford University Press, 2001.

23. MACEDO TFS. Hepatites virais-uma revisão de literatura. Brazilian Journal of Surgery and Clinical Research. 2014.

24. MOTA ACC, et al. Hepatites virais na infância: perfil epidemiológico dos pacientes pediátricos do estado do Pará. Brazilian Journal of Health Review, 2020; 3(4): 8775-8784.

25. PAULA VS, et al. Manual de Hepatites Virais. 1. ed. - Rio de Janeiro: Rede Sirius; OUERJ. 2015; 215.

26. SÃO PAULO. Governo do Estado de São Paulo. Secretaria de Estado de Saúde de São Paulo. DI/DH/CVE/CCD/SESSP. Centro de Vigilância Epidemiológica "Prof. Alexandre Vranjac". Coordenadoria de Controle de Doenças. Informes técnicos institucionais. Vacina contra hepatite B. Rev. Saúde Pública vol.40 n.6. 2006. Disponível em: https://www.scielo.br/scielo.php?script=sci_arttext\&pid=S0034-89102006000700026. Acessado em: 06/02/2021

27. TIMÓTEO MVF, et al. Perfil epidemiológico das hepatites virais no Brasil. Research, Society and Development, 2020; 9(6): e29963231-e29963231.

28. ZORZETTO R. Pesquisa Fapesp. 2011. In: O mapa das hepatites. São Paulo: Fundação de Amparo à Pesquisa do Estado de São Paulo, edição 187. Disponível em: https://revistapesquisa.fapesp.br/o-mapa-das-hepatites/. Acessado em: 03/02/2021. 